\title{
Research on the Development of Internet Finance
}

\author{
Chen Hongxian \\ Hangzhou College of Commerce, Zhejiang Gongshang University, Hangzhou, China
}

\section{Email address:}

hezlwa54jujz@163.com

\section{To cite this article:}

Chen Hongxian. Research on the Development of Internet Finance. Science Innovation. Vol. 5, No. 6, 2017, pp. 409-415.

doi: $10.11648 /$ j.si.20170506.24

Received: November 13, 2017; Accepted: December 19, 2017; Published: December 28, 2017

\begin{abstract}
At present, with the acceleration of China's economic development speed, and people's understanding of the financial industry is gradually deepened, prompting more and more people, the disposable funds into the financial products. At the same time, due to the entry of Internet plus time, wide application of computer technology, network technology, information and communication technology in the financial industry, to promote a more efficient and convenient financial services, Internet financial service mode gradually surfaced, and perceptions of the Internet financial services with the deepening of the Internet makes financial showing a more the rapid development trend. Its emergence not only opens up a new conception and path for the development of the financial industry, but also provides a reference for the network development of the financial industry. When the Internet plus era into the Internet financial times, both in the management, provides a difficult situation for dealing with government regulators, and expand the areas for the financial industry, laying a solid foundation for the next. This makes the study of the development of the Internet finance, will have great practical significance. In this regard, this article through the literature method and SWOT analysis method, the present condition of the development of Internet banking, the existing problems in the development, make a thorough analysis and research and corresponding countermeasures, and finally draws the conclusion: financial service mode based on Internet environment, not only has the advanced science and technology as the support. And then show a broader space for development, has more market prospects and strong vitality, in the process of financial development of the Internet, according to government regulators, Internet financial practitioners, and Internet banking participants multi-party cooperation and coordination, and construct a perfect Internet financial supervision mechanism, in order to promote internet financial on sustainable development to a new level.
\end{abstract}

Keywords: Internet Finance, SWOT Law, Regulatory Function

\section{互联网金融发展研究}

\section{陈宏献}

杭州商学院, 浙江工商大学, 杭州, 中国

邮箱

hezlwa54jujz@163.com

摘要：当前，随着中国经济发展速度的不断加快，以及人们对于金融行业的了解逐步加深，促使越来越多的人群，将 可支配资金注入到金融理财产品中。同时，由于互联网+时代的进入，计算机技术、网络技术、以及信息通信技术在 金融产业中的广泛应用，促使更加高效、便捷的金融服务方式一互联网金融服务模式逐渐浮出水面，且随着人们对 于互联网金融服务认知程度的加深，使得互联网金融呈现出更为快速的发展态势。它的出现，不仅为金融行业的发展 开辟出全新的构想与路径, 更为金融产业的网络化发展, 提供出可供参考与借鉴的内容。正值互联网+时代的进入时 期, 互联网金融既在管理上, 为政府监管部门提供了艰巨的应对局面, 又为金融行业的领域拓展, 奠定下坚实的基础。 这使得此时对互联网金融的发展做出研究, 将具有极大的现实意义。对此, 本文通过文献法和SWOT分析法, 对互联 网金融的发展现状, 发展中所存在的问题, 以及与之相对应的应对措施等做出细致的分析与研究, 并最终得出结论: 
基于互联网环境下的金融服务模式，不仅具有先进的科技为支撑，进而展现出更为广阔的发展空间，更具有超强的市 场前景与活力, 在进行互联网金融发展过程中，需要结合政府监管部门、互联网金融从业者、以及互联网金融的参与 者等多方的协作与配合，并同步构建起完善的互联网金融监管机制，以此促使互联网金融在可持续发展上，迈上崭新 的台阶。

关键词：互联网金融, SWOT法，监管职能

\section{1. 引言}

新时代背景下，社会的发展和科技的进步，以及互联网 技术在各个行业及领域内愈加广泛的应用, 促使人们对于网 络模式下的产品与服务, 得到了更为深入的了解与认知。这 也使得“互联网金融”一词，开始逐步进入到人们的日常生活 之中，且从互联网金融词汇的兴起，便给原本趋于稳步发展 的金融行业, 带来了一记威力极大的重磅炸弹。如果说人们 对于互联网金融的了解和认知, 还相对贵乏阶段, 那么阿里 巴巴公司联合天弘基金, 并在2013年所投入网络金融市场的 “余额宝”, 则成为众所周知, 家喻户晓的“互联网金融拳头 产品”[1]。由于阿里巴巴公司旗下的“淘宝”、“天猫”等电子 商务平台, 已然转化或积累出大量的网络用户, 这使得“余 额宝”一进入市场, 便引起了广大网络用户的浓厚兴趣。据 阿里巴巴所做出的数据统计, “余额宝”在2013年的6月13日 进入市场后, 经过短短 18 天的宣传与运营, 截至2013年7月1 日，便以为“余额宝”，而收获网络用户 250 余万人，累计转 入资金也达到66亿元。其中仅用作消费的金额，便已超过 12 亿人民币 2 亿。而截至 2017 年 10 月，余额宝则共积累用户 2.6 亿人，使其成为中国互联网金融市场中，极具代表性的增利 货币基金产品。由此, 2013年便被众多金融专家及学者们称 之为“互联网金融元年”。[3]在余额宝取得大块互联网金融市 场后, 与之相类似的产品也逐步进入互联网金融市场, 如时 下较为流行的腾讯的理财通、悟空理财、京东金融等等。且 此类产品所具有的特征均较为明显, 如收益率较高、准入门 槛较低、操作简便、以及可进行实时的买入赎回操作。这与 传统金融产品相比, 无异于具备了极强的市场优势。而此种 互联网金融产品, 能否持续性的为互联网金融产业的发展, 贡献出源源不断的动力, 且互联网金融现有的中国金融经济 环境下, 又具有哪些优势与劣势, 文中会进行细致且明确的 分析, 意在为中国互联网金融产业的发展, 迎来更为宽广的 市场前景和发展空间[4]。

\section{2. 互联网金融概述}

\section{1. 互联网金融的内涵}

所谓互联网金融,即是以移动技术、云计算、社交网络、 以及搜索引擎等网络化工具, 促进资金在网络环境下实现融 通、移动支付、和信息中介等功能的金融服务产物，更是传 统金融行业与互联网技术相结合后的全新金融领域。

对于互联网金融而言, 其内涵可表现在针对互联网环 境的平等、合作、开放、以及分享等方面, 是将传统金融 领域中的知识与内容, 沿用到网络化的金融市场之中, 通 过网络化的数据信息传递与接收方式, 以及更为快速、便
捷的操作模式，实现低成本、高透明度的金融业务。而广 义上的互联网金融，不仅仅涉及到网络投资基金、虚拟货 币、以及网络化的理财等方面, 更囊括了第三方支付、 $\mathrm{P} 2 \mathrm{P}$ 网络贷款、以及众筹等内容[5]。

\section{2. 互联网金融的特征}

互联网金融与传统金融模式相比，具有较为明显的差 异性特征，而这些差异性特征也为互联网金融在金融行业 中的融合与发展, 奠定下良好的差异化基础。如下图1所示。

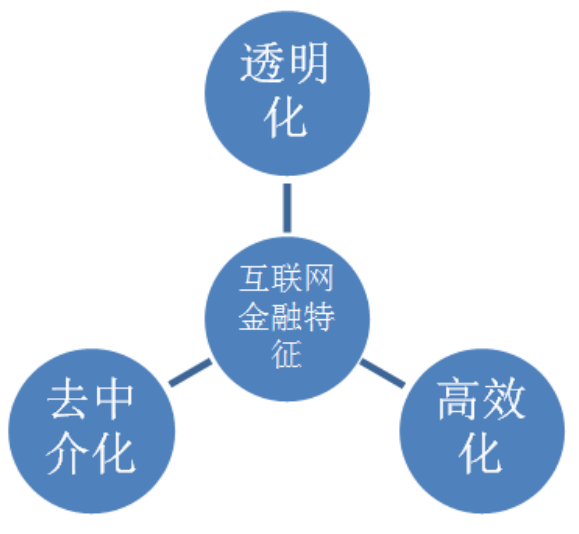

图1 互联网金融特征示意图。

\subsection{1. 透明化特征}

传统金融模式下, 银行与信贷等金融机构为更为精细 的了解和掌握拟投资企业的资金情况及经营现状等信息, 不仅要从多个渠道进行该企业各类相关信息的收集, 更要 对拟投企业进行细致的评估与考察，只有通过大量真实、 有效的数据信息, 表明拟投企业的经营状况和资金情况良 好, 且无不良记录, 才能由此出具借贷的可行性报告, 并 通过层层审批办理借贷的相关事宜。不仅会消耗大量的时 间, 更会带来不必要的成本投入[6]。而通过互联网金融模 式，便可随时随地的进行金融产品的交易，且拟投企业的 相关信息等, 也会通过网络中的大数据来获取, 如此便可 在网络环境下, 促进交易双方自由的获取或供给出所需的 各类信息, 不仅便于财务状况及信用等级的详细掌握, 更 会解决交易双方信息不对称等现象。而此种实时、高效、 且准确的信息获取来源, 便得益于网络环境, 从而使得互 联网金融具备了透明化的特征。

\subsection{2. 高效化特征}

对于互联网金融而言，其业务范围遍布全球，且业务 形式更是复杂多样, 但无论如何多样化的互联网金融业务 模式, 都是通过计算机技术、网络技术、以及信息通信技 
术等共同构成的[7]。且无论何种互联网金融业务种类，所 进行的流程操作也均相同, 不仅处理速度快, 且用户体验 度好。就现阶段软件市场上较为流行的几款互联网金融 APP而言（㺵富、借贷宝、支付宝（余额宝）、京东金融 等), 从注册、个人信息填写、贷款申请, 再到贷款发放, 全程仅需几分钟，真正做到了方便快捷。这便体现出互联 网金融的高效化特征。同时，互联网金融所获取的信息来 自于大数据网络和更多的电子商务平台, 这也使得互联网 金融在发展速度上, 也具有极强的高效化特征, 其中余额 宝的案例, 便是互联网金融具备高效化特征的另一佐证。

\subsection{3. 去中介化特征}

传统金融模式中，进行资金借贷的企业或个人，很多 情况下会因项目的开展或其他投资需求, 而对金融机构进 行信贷的申请，但银行等金融机构却无法及时、精确的发 挥出贷款作用, 除调查、审批等流程繁琐之外, 信用度的 获取及金融风险的设定, 是限制贷款的另一大因素。此种 情况会导致很多情况下, 贷款者的需求无法通过银行等金 融机构得到满足 [8]。而银行等金融机构, 则更愿意将资金 贷给大中型, 或具有国家担保的国有企业, 如此来降低信 贷过程中所出现的不良贷款率。随着互联网金融模式的兴 起, 越来越多的小微企业和个人, 在 $\mathrm{P} 2 \mathrm{P}$ 网贷平台中获取 到贷款, 很大程度上解决了小微企业及个人的需求或燃眉 之急。其与传统金融机构的区别在于: 互联网金融体系中, 很多进行资金筹集的贷款平台，仅通过众筹或募集资金等 方式，把社会中具有闲散化和碎片化的资金进行收集，并 将其应用到有需求的企业或个人身上。这其中完全是点对 点（Peer to Peer）的沟通与交易, 只要符合借贷的基本条 件，便可快速的获取到相应金额的贷款资金 [9]。

\section{3. 中国互联网金融发展现状分析}

\section{1. 中国互联网金融产品概述}

虽然中国的互联网金融起步较之2013年要更早一些, 但一些专家学者们, 仍愿意将2013年称之为中国互联网金
融元年, 对此, 本文也依照2013年为界限, 对互联网金融 在近年来所推出的产品进行简要阐述。

自2013年阿里巴巴与天弘基金联合推出余额宝之后, 中国其他家知名的电子商务公司, 也陆续兴起了推出各类 “基金”或“理财”产品的发展之路，如㺵富、借贷宝、京东 金融等。而此类产品的推出, 还仅仅是在中国较为知名, 或具有不俗经济实力的企业或公司所做出的针对性产品 退广, 但此举也带来了中国互联网金融产业的发展热潮, 致使很多小规模的企业或个人信贷人员, 都对互联网金融 的发展趋之若鷔, 纷纷寻求软件开发公司, 推出以众筹资 金为目的的 $\mathrm{P} 2 \mathrm{P}$ 网贷平台，随着手机保有量和移动网络的 覆盖面日益广泛, 此类小规模企业及个人又纷纷进驻移动 终端, 结合互联网信贷平台, 设置出移动端的基金或理财 APP [10]。此类理财或基金类软件, 仅在ISO平台中, 便已 有几十种, 而在应用系统更为广泛的Android平台中, 更 是达到了上百种软件应用, 这也表明中国互联网金融产品 的出现，不仅仅是产业发展所生成的偶然结果，而应当是 产业发展过于迅速，而缺乏有效金融监管的产物。

\section{2. 中国互联网金融监管}

中国的传统金融行业中, 所采用的监管方式为分业经 营后的分业监管。如银行、证券公司、以及保险公司, 是 中国金融行业的重要组成部分, 而对此进行监管的部门分 别是银监会、证监会、以及保监会。对于成型已久的金融 体系而言, 较为完善的金融监管框架也构成已久。而随着 互联网金融的出现及发展, 传统的金融监管方式已然无法 满足或制约互联网金融的发展步伐, 对此, 中国针对与网 络化的银行、证券、以及保险公司等，陆续出台了一系列 的监督与管理办法 (如下表1所示)，但作为监管部门而 言, 仍然未能针对互联网金融的模式与发展趋势, 制定出 颇为完善的监管措施, 很多方面仍然存在漏洞或空白 [11]。 例如: 与P2P网贷平台相关的监管政策及法律等, 便仍具 有诸多需要填补的政策及法律空白, 致使准入门槛过低、 紧急监控缺位、风险评估不足、交易双方信息不对称、以 及信息披露机制不健全等问题依然在一定范围内存在。

表1 网络主体法规或管理办法汇总表。

\begin{tabular}{llll}
\hline 网络主体 & 颁布时间 & 颁发单位 & 名称 \\
\hline 网上银行 & 2005.11 & 银监会 & 《电子银行业务管理办法》 \\
& 2005.11 & & 《电子银行安全评估指引》 \\
网上证券 & 2012.5 & 《关于修改<证券发行与承销管理办法>》 \\
& 2000.3 & 证监会 & 《网上证券委托暂行管理办法》 \\
网上保险 & 2011.4 & & 《互联网保险业务监管规定》 \\
& 2011.9 & 保监会 & 《保险代理、经济公司互联网保险业务》 \\
条上支付 & 2005.10 & 《电子支付指引 (第一号)》 \\
& 2010 & 中国人民银行 & 《非金融机构支付服务管理办法》 \\
& & 《非金融机构支付服务管理办法实施细则》 \\
\hline
\end{tabular}

\section{4. 互联网金融发展的SWOT分析}

依据上文中, 中国互联网金融发展现状的表述，采用 SWOT法, 对现阶段中国互联网在发展中所出现的优势、 劣势、机遇、以及威胁等情况做出进一步的分析, 以期为
互联网金融发展中问题的解决, 明确出存在问题的方面, 及生成原因[12]。

\subsection{SWOT分析}

SWOT分析法作为一类态势分析方式, 能够对研究对 象做出内部优势与劣势, 以及外部机会与威胁等方面的细 
致分析与把控, 并通过矩阵图形式将研究对象所遇到的问 题罗列而出, 再进一步对所存在于矩阵图中的相关因素做 出联合性分析。此种SWOT分析法的根本目的, 在于对研
究对象的全方位了解和掌控, 以便由此制定出更具针对性 的解决措施。其矩阵分析图如下图2所示。

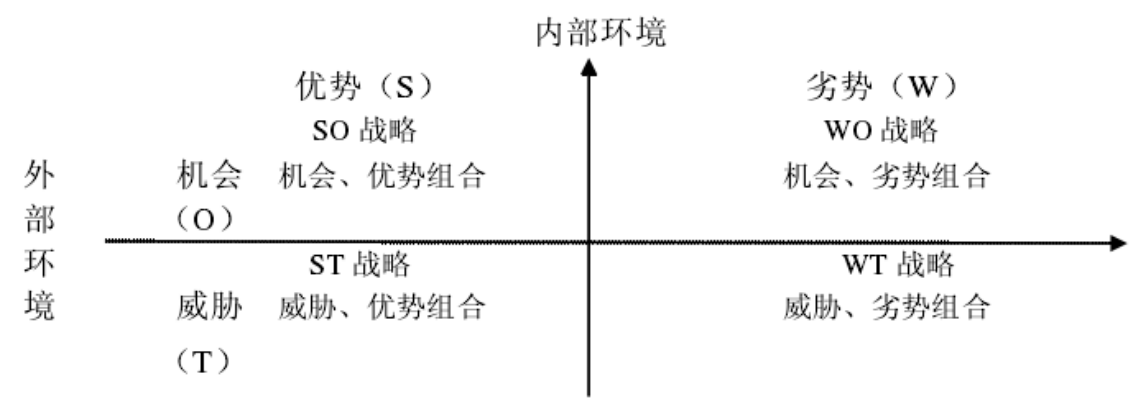

图2 SWOT矩阵分析示例图。

\section{2. 互联网金融的优势分析}

\section{2. 1. 具备先进的信息技术}

互联网金融的良好发展, 会因大数据时代中海量网民 数据信息的获取, 而带来更为快速、高效的发展势头。这 其中所涉及到的几方面要素则必不可少。首先, 云计算。 对海量数据信息进行及时, 且计算速度、存储能力、以及 服务功能等, 都是云计算所具备的典型特征, 也是解决互 联网金融问题的必要手段 [13]。其次, 移动支付。现阶段, 移动支付泛指手机支付, 即是用户通过移动终端进行购买 产品的付款方式。随着手机保有量的提升, 以及互联网技 术的日益成熟，中国产业信息网在2017年10月进行了未来 中国移动互联网市场规模的推断（如下图3所示）

2014-2018年中国移动互联网市场规模

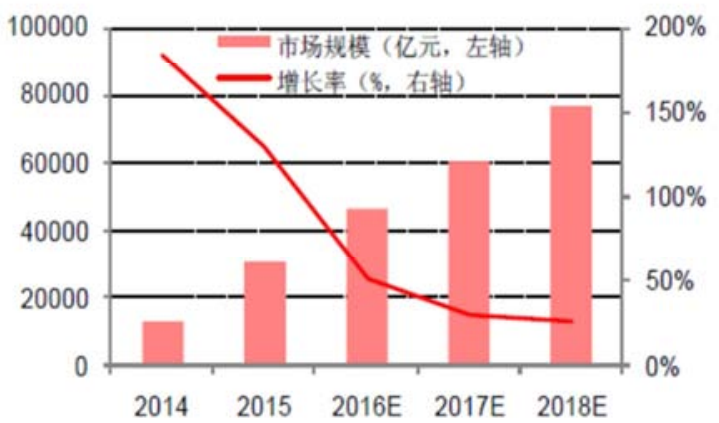

图3 2014-2018年中国移动互联网市场规模。

人们消费意识的提升、网络知识的加强、以及方便 快捷操作流程的指引, 能够与移动互联网的发展规模相 结合, 并碰撞出更为热烈的火花, 这也促使移动支付方 式，成为互联网金融产业的巨大信息技术优势。再次， 社交网络（SNS Social Network Service）。社交网络中涵 盖软、硬件, 各类服务及应用等[14]。从互联网发展现状 来看, 人们由于各类原因 (生活压力大、表达能力差、 以及善于分享等），会对网络化的社交模式形成较强的 依赖性。据不完全统计, 在对近年来《中国网站运营发
展调查报告》的研究后发现, 较多的互联网优质资源会 来自于社交网络之中, 且其排名稳居首位[15]。尤其是微 信、QQ、以及微博等社交网络平台或即时通信软件的普 及, 更使得人与人之间的交互性增强, 这也使得互联网 金融产品, 得以在更为流通的环境中被了解和熟知。

\subsection{2. 对金融行业的促进}

2014年起，中国银监会首次提出选取民营资本参与 民营银行试点的协同发展, 这一举措预示着互联网金融 的发展, 将会对传统金融产业带来多方面因素的影响, 促进传统金融产业的格局发生变化。而互联网金融对传 统金融行业的促进和影响，也体现在以下几方面内容上。 首先，活力的注入。互联网金融通过不断的发展，为金 融市场带来了充分的活力, 究其根源, 是由互联网金融 产生的原因相关, 即解决各个行业及领域消费群体或个 人消费者的金融需求。由于消费者对金融的诉求随互联 网时代的到来而不断攀升, 唯有通过全新的互联网金融 模式, 才能更为快速、精确的解决此类问题, 这便导致 互联网金融的产生与发展, 为金融市场创造出巨大的空 间和活力 [16]。其次，健全体制的促进。互联网金融的发 展，是便于社会诚信体系构造的，其所构成的金融产品 更是促进网络诚信环境的重要基础。由于网络化社会中 信息的高速传递，为人们的行为敲响了规范性的警钟， 唯有时刻约束不正当的行为，使其时刻处于良好的信用 标准之内, 才能在更多社会行为中获取到既得的利益, 也才能延续可持续发展的模式。而互联网金融的产生, 也将为传统金融行业做出了网络化的信用体系补充，促 使金融体系的完善性构建。

\section{3. 互联网金融的劣势}

互联网金融是传统金融模式与网络技术相结合的产 物，传统金融模式所具有的风险类型，也应同步归属于 互联网金融的风险种类之中, 且会因网络化的金融模式, 而涉及到网络化的风险类型。首先, 量化放贷风险。互 联网金融产品多为依托大数据所构建起来的量化放贷模 型, 利用整合数据筛选目标用户、进行贷款额度的核算、 以及贷款的发放。而与传统金融机构不同，互联网金融 并没有较强的吸储能力, 且无法获取到充足的资金流动, 
这使得其在发展过程中, 便要承担比传统金融更为大的 风险[17]。同时,经济形势与量化放贷间具有紧密的联系, 若互联网金融机构无法对经济走势做出精确的预估, 则 将产生较大的量化放贷风险。其次, 技术安全风险。网 络化的金融模式需要承担网络安全风险, 如病毒、木马 等。若进行交易的计算机及网络感染病毒, 则会导致大 量用户信息被盗取, 甚至整体信息系统㿈疾, 难以维持 金融发展的稳定性。并且, 来自于人员违规操作所引起 的计算机宕机或储存数据丢失, 都将促使安全风险的提 升。最后, 法律风险。现阶段, 中国尚未建立起针对互 联网金融的网络化金融监管法律体系, 这使得互联网金 融市场准入门槛低、信息不对称、以及交易主体间权利 与义务划分不明确等问题。这不仅会导致交易成本的递 增, 更会是互联网金融的发展受到严重的制约。并且, 受互联网金融透明化特征的影响, 很多涉及到用户因素 的信息, 无法通过健全、合理的法律条文对其进行保护， 致使法律风险生成。

\section{4. 互联网金融的发展机遇}

随着中国经济发展速度的不断加快, 以及鼓励创业、 帮扶小微企业构建政策的实施，促使中小企业得以快速发 展, 而中小企业在发展中所面临的融资难问题, 是显著影 响或制约其发展的主要因素。而此时, 互联网金融的发展, 将会对中小企业融资难问题, 带来良好的解决措施, 并同 时为中小企业开辟出良好的金融环境。如降低了中小企业 的经营成本, 促进小额贷款的成功率; 促进了信贷趋于订 单化和规模化, 简化信贷作业流程等。同时, 由于政府职 能监管部门充分意识到互联网金融的发展, 需要通过行业 自身的发展与开拓, 进而对互联网金融秉承政策放宽性的 “创新成长”促进原则 [18]。对此, 不仅人民银行副行长刘 士余在《秉承包容与创新的理念, 正确处理互联网金融发 展与监管的关系》中提出: “细致梳理互联网金融在中国 金融行业中的发展, 通过科学、合理的放宽方式, 进行中 国互联网金融的促进性发展”, 为互联网金融的发展开辟 了良好的成长条件, 且央行行长周小川也在《求是》中表 明: “推动包容性金融发展, 坚持民生金融优先, 鼓励金
融创新, 完善政策支持体系, 让广大人民群众共享金融改 革和发展的成果”, 这也为互联网金融的发展营造出更为 广泛的空间和更为多样化的机遇。

\section{5. 互联网金融的威胁分析}

首先, 监管威胁。随着互联网金融的发展, 电子货 币营运而生, 但电子货币的出现, 会在一定程度上影响 与限制传统货币体系的发展，促使金融行业提升风险的 同时，增加了货币杜杆。对于互联网金融而言，其在通 过对闲置资金全新金融理财模式运用，使其已然具备“准 商业银行”性质，若发生借贷关系，则网络化的“货币创 造” 能力, 便会得以释放, 促使货币M2过量。其次, 收 益率威胁。互联网金融之所以能够在短时间内筹集到大 量的资金, 不仅是受到网络化模式的促进, 还有较大部 分原因, 是来自于较传统金融机构偏高的年化收益率。 现阶段, 各类互联网金融产品所提供的年化收益率数据, 基本在3.5 5.2\%之间, 这在平均水平上要远高于传统金 融机构所能给付到的收益比例。然而, 2017年互联网金 融产品的年化收益率，又较之2014 2015年间的7\%收益 率下降比例偏高, 因而互联网金融在发展中所存在的收 益率威胁也是必然存在的 [19]。

综上所述, 通过对互联网金融的SWOT分析不难看 出, 互联网金融的发展显然利大于弊, 但基于所存在的 劣势与威胁等问题, 则也要通过完善的解决措施予以降 低或消除, 以此促使互联网金融在可持续化的道路上蓬 勃发展。

\section{5 . 互联网金融发展中问题的解决措施}

\section{1. 加快互联网金融的健全性立法}

互联网金融的立法不可一蹴而就, 需要通过多角度、 多层次、以及进行步骤的划分等工序, 并结合金融行业及 网络技术的特点, 做出针对性的设计与构建。如下图4所 示。

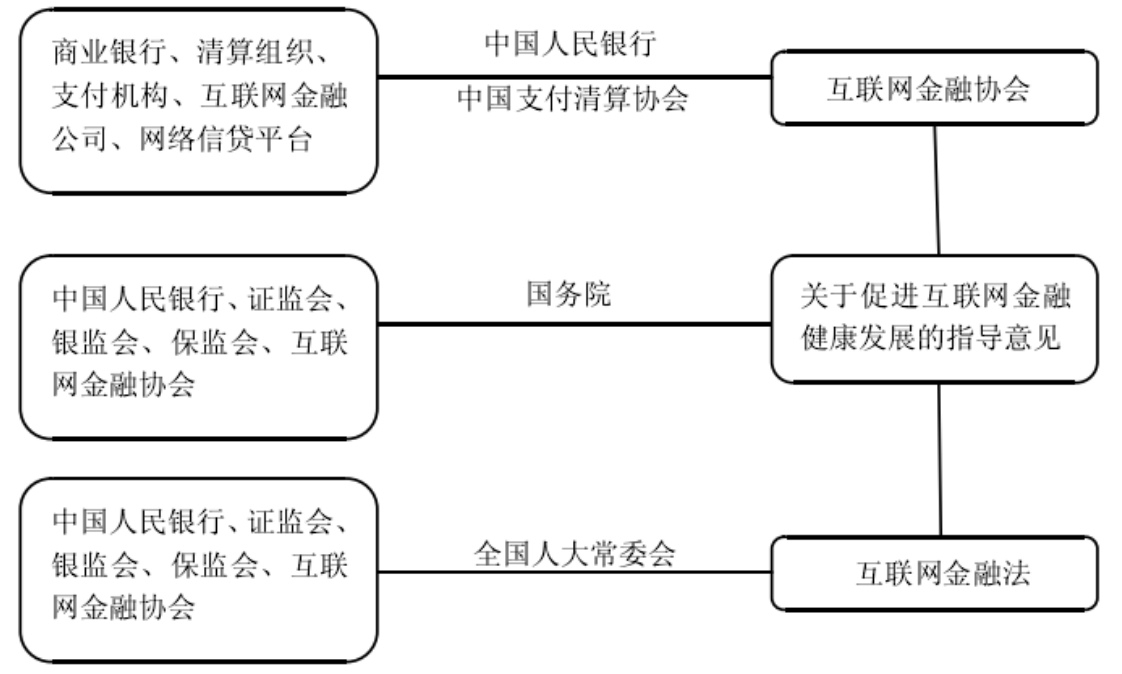

图4 未来互联网金融立法设计图。 
其中, 第一层内的互联网金融协会, 能够进行行业自 律组织工作, 通过此部门的建立, 能够对互联网金融企业 间的数据信息与资源等进行及时、准确的协调, 并同步进 行各类资源的共享，从而消除互联网金融行业内的不良竞 争现象。同时, 金融协会也会设定出互联网金融行业的章 程与制度, 以此来规范和限定互联网金融市场的行为。且 在受到利益侵害时, 也能通过金融协会做出协调和行业内 制裁。第二层内的国务院在针对互联网金融发展工作中, 颁布了《关于促进互联网金融健康发展的若干意见》, 内 容不仅对现阶段的互联网金融做出了精确的市场定位, 并 对组织形式与监管内容等做出规范, 是互联网金融行业发 展的指导性文件。第三层的全国人大常委会, 更是针对互 联网金融发展现状, 颁布了《互联网金融法》。此项法律 法规不仅具有最高规格的法律效力, 且同时对互联网金融 行业的准确定义、市场准入标准、经营限定范围、以及监 理工作开展等, 做出了更为精确性的法律约束。这对于互 联网金融的立法健全性, 也将起到极为重要的促进作用 [20]。

\section{2. 加强互联网金融信息体系构建}

首先, 推行实名制金融信用等级。对此, 应在用户填 写个人相关信息时, 进行身份验证, 并依据互联网特点, 为用户建立起自身的准确身份档案, 如互联网身份证的设 定, 以及电子签名档的设立等。同时。互联网金融机构, 也应从注册资本、运营现状、机构资质等方面进行严格的 把关, 对不符合要求, 或资质欠缺的金融产品申请人等, 要将其拒之门外, 若存在申请人申报时出现虚假信息或信 用欺骗, 则对其信息在网络公众平台中进行公布, 一方面 对信用欺骗者做出警示, 另一方面为行业内的其他机构擦 亮眼睛。使信用欺诈现象无所遁形。其次, 建立信用评分 制度。这不仅需要互联网金融机构对申请用户的信用等级 记性评分, 更要促进用户对互联网金融机构进行信用的评 分, 且应作出严格的限定, 即信用等级处于较低档时, 便 无法通过互联网金融模式进行金融产品的购买, 以及相关 贷款的办理。与此同时，互联网金融机构也应对自身的从 业人员, 进行专业化的信用知识培训和信用意识教育, 促 使互联网金融从业人员在自身具备良好信用等级的基础 上, 为客户提供出更为专业和安全的服务。

\section{3. 建立互联网金融监管协调机制}

在互联网金融监管机制的建立上，应从以下两个方 面进行对策的实施。首先, 对货币政策与金融监管工作 做出协调。促进金融产业稳定, 维护市场体制的经济发 展，是货币政策与金融监管政策所共同面临的问题。一 方面，金融市场及相关金融机构稳步发展，则货币政策 能够有效实施; 另一方面, 金融监管政策在制定方面, 离不开对宏观经济的精确分析, 而货币政策便是宏观经 济环境中, 极为重要的构成内容。在互联网金融环境下, 电子货币的发行无需实物货币作为发行准备, 这将导致 互联网金融货币的创造功能会显著增强, 由此便会影响 到货币乘数与流通速度, 而如此一来, 货币政策形同虚
设。并且互联网金融对于精确数据信息具有极强的依赖 性, 而数据信息的精确性, 则来源于良好的经济形势, 若货币政策受到影响, 则实体经济便会受到影响, 进而 影响到互联网金融的准确判断。因此, 应对货币政策与 金融监管政策进行细致的协调。其次, 对金融监管与法 律法规做出协调。金融监管工作离不开法律法规的理论 依据, 而法律法规的制定, 则是为更为完善化的监管工 作达成。但两者应处于相对平衡且稳定的局面下。若法 律法规过多, 则会造成互联网金融产业的发展受到严重 的制约, 且在监管工作的开展上, 也设立其了过稿的门 槛, 而若金融监管工作增多, 则会致使监管成本居高不 下, 且效率却难以提升。

\section{6. 结论}

综上所述, 随着人们网络交易意识的提升, 以及网络 技术的飞速发展，互联网金融行业得到了较大的发展空间。 但就现阶段互联网金融的发展现状分析, 其具有较为明确 的优势与发展机遇, 但仍旧存在较为明显的问题与威胁。 对此，应从互联网金融行业立法、金融监管体系构建、以 及信用体系建立等方面采取措施。同时, 应通过积极政策 的扶持, 对互联网金融的发展构建起规范化的路径。唯有 如此, 才能确保中国互联网金融行业得以健康、稳步的发 展, 也才能为传统金融行业开辟出更为广阔的发展空间。

\section{参考文献}

[1] 胡光志, 周强. 论我国互联网金融创新中的消费者权益保护 [J].法学评论, 2014,32(06):135-143。

[2] 田光宁. 互联网金融发展的理论框架与规制约束 [J]. 宏观经 济研究, 2014,(12):42-48+111。

[3] 郑联盛. 中国互联网金融: 模式、影响、本质与风险 $[\mathrm{J}$. 国 际经济评论, 2014,(05):103-118+6。

[4] 曹风岐. 互联网金融对传统金融的挑战 [J]. 金融论坛, 2015,20(01):3-6+65。

[5] 王国刚, 张扬. 互联网金融之辨析 [J]. 财贸经济, 2015,(01):5-16。

[6] 李平, 陈林, 李强, 冯毅, 赵洪江. 互联网金融的发展与研 究综述 [J]. 电子科技大学学报, 2015,44(02):245-253。

[7] 杨东. 互联网金融风险规制路径 [J]. 中国法学, 2015,(03):80-97。

[8] 汪炜, 郑扬扬. 互联网金融发展的经济学理论基础 [J]. 经济 问题探索, 2015,(06):170-176。

[9] 曾建光. 网络安全风险感知与互联网金融的资产定价 [J]. 经 济研究, 2015,50(07):131-145。

[10] 沈悦, 郭品. 互联网金融、技术溢出与商业银行全要素生产 率[J]. 金融研究, 2015,(03):160-175。 
[11] 谢平, 邹传伟, 刘海二. 互联网金融的基础理论 $[\mathrm{J}]$. 金融研 究, 2015,(08):1-12。

[12] 周光友, 施怡波.互联网金融发展、电子货币替代与预防性 货币需求 $[J]$. 金融研究, 2015,(05):67-82。

[13] 王馨. 互联网金融助解“长尾”小微企业融资难问题研究 [J]. 金融研究, 2015,(09):128-139。

[14] 李继尊. 关于互联网金融的思考 [J]. 管理世界, 2015,(07):1-7+16。

[15] 互联网金融国家社科基金重大项目课题组, 张兵, 孙武军. 互联网金融的发展、风险与监管一互联网金融发展高层 论坛综述[J]. 经济研究, 2015,50(11):183-186。

[16] 何飞, 张兵. 互联网金融的发展: 大数据驱动与模式衍变 $[\mathrm{J}]$. 财经科学, 2016,(06):12-22。
[17] 李有星, 陈飞, 金幼芳. 互联网金融监管的探析 $[\mathrm{J}]$. 浙江大 学学报(人文社会科学版), 2014,44(04):87-97。

[18] 陶娅娜. 互联网金融发展研究 [J]. 金融发展评论, 2013,(11):58-73。

[19] 袁博, 李永刚, 张逸龙. 互联网金融发展对中国商业银行的 影响及对策分析 [J]. 金融理论与实践, 2013,(12):66-70。

[20] 汤臬. 规范互联网金融发展与监管的思考 [J]. 金融会计, 2013,(12):55-59。

[21] 刘沙沙. 浅析P2P网贷平台下中国中小企业融资现状 [J]. 西 部皮革，2017,39(12):94。 